\title{
Penggunaan Pendekatan Healing Architecture dan Konsep Therapeutic Spaces pada Rancangan Fasilitas Rehabilitasi Sosial bagi Korban Narkoba
}

\author{
Nabilla Fadlina Azhari dan Murni Rachmawati \\ Departemen Arsitektur, Fakultas Teknik Sipil dan Perencanaan, Institut Teknologi Sepuluh Nopember (ITS) \\ e-mail: murnirach@arch.its.ac.id
}

\begin{abstract}
Abstrak-Narkoba merupakan zat-zat dan obat-obatan terlarang yang berbahaya untuk tubuh manusia apabila dikonsumsi dalam jumlah berlebihan. Indonesia saat ini sudah masuk menjadi negara darurat narkoba. Telah banyak upaya yang dilakukan pemerintah dalam menangani masalah tersebut, salah satunya adalah dengan meningkatkan kualitas rehabilitasi dan fasilitasnya. Therapeutic community adalah metode penyembuhan yang digunakan dalam rehabilitasi sosial korban narkoba. Konsep utama dari metode ini memiliki motto "Helping man help himself". Metode penyembuhan tersebut dapat diterapkan melalui konsep therapeutic spaces. Therapeutic spaces dapat dideskripsikan sebagai lingkungan terbangun yang berpusat pada manusia, disiplin evidence-based, yang bertujuan untuk mengidentifikasi dan mendukung elemen spasial yang berinteraksi dengan fisiologi dan psikologi manusia. Objek dirancang menjadi wadah dari aktifitas rehabilitasi sekaligus menjadi bagian dari proses penyembuhan. Setiap elemennya harus mendukung penyembuhan penggunanya. Dengan begitu diharapkan fasilitas dapat menjadi sebuah objek arsitektur yang kondusif untuk rehabilitasi dan mendukung aspek-aspek penyembuhan penggunanya mereka dapat menjadi produktif dan kembali ke masyarakat.
\end{abstract}

Kata Kunci-Narkoba, Rehabilitasi, Sosial, Healing architecture, Therapeutic Spaces.

\section{PENDAHULUAN}

I NDONESIA saat ini sudah masuk menjadi negara darurat narkoba. (Gambar 1) Menurut data BNN, akibat penyalah gunaan narkoba, setiap hari 50 orang meninggal dunia, sedangkan setiap tahun 18 ribu orang meninggal dan 4,5 juta orang harus direhabilitasi. Selain itu, kerugian yang ditimbulkan akibat narkoba mencapai 63 triliun Rupiah yang meliputi biaya pembelian narkoba, biaya pengobatan dan biaya rehabilitasi akibat narkoba [1].

Berbagai upaya telah dilakukan untuk memberantas narkoba. Di Indonesia saat ini digencarkan upaya pemberantasan narkoba. BNN telah menyusun rencana pemberantasan narkoba dengan berbagai cara, yang paling utama adalah supply reduction dan demand reduction. Untuk demand reduction dilakukan dengan merehabilitasi penyalah guna narkoba sesuai dengan pasal 54 UU No. 35 tahun 2009 tentang narkotika, tertulis bahwa "Pecandu Narkotika dan korban penyalahgunaan Narkotika wajib menjalani rehabilitasi medis dan rehabilitasi sosial".
Rehabilitasi dilakukan agar korban tidak menggunakan narkoba lagi dan mengedukasi masyarakat, utamanya kalangan rawan terjebak narkoba, tentang narkoba dan dampak serta kerugian menggunakannya.

Therapeutic community adalah metode penyembuhan yang digunakan dalam rehabilitasi sosial korban narkoba. (Gambar 2) Metode ini bersifat partisipatif dan group-based. Konsep utama dari metode ini adalah menolong diri sendiri atau $\neg$ selfhelping, dan memiliki motto "Helping man help himself" [2]. Metode ini biasanya dilakukan secara residensial, dimana selama proses penyembuhan pasien tinggal di fasilitas rehabilitasi dengan terapis. Tujuan utamanya adalah menolong dan menyadarkan pasien agar mampu kembali ke tengah masyarakat dan menjalani hidup yang produktif kembali.

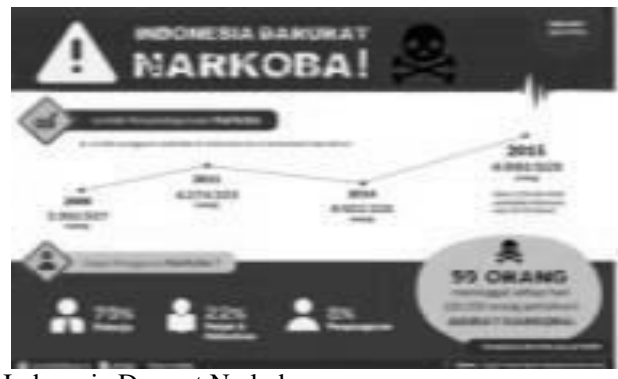

Gambar 1. Indonesia Darurat Narkoba.

Sumber: kominfo.go.id

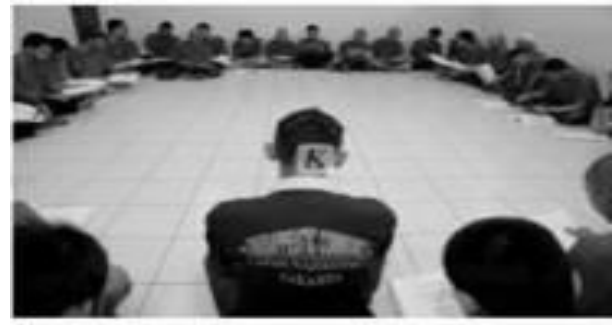

Gambar 2 . Metode penyembuhan Therapeutic Community. Sumber: kompasdata.id

\section{METODA PERANCANGAN}

Pendekatan utama yang digunakan adalah healing architecture. Healing architecture adalah sebuah konsep desain dimana arsitektur turut serta dalam proses penyembuhan pengguna. (Gambar 3) Pendekatan ini sering digunakan pada perancangan fasilitas kesehatan. 
Arsitektur dan desain dapat mendukung proses penyembuhan dengan dukungan di aspek psikologis dan fisik pasien. Sebuah fasilitas kesehatan butuh untuk berkontribusi secara aktif dengan merelaksasi dan mengembalikan kembali semangat hidup pasien.

Aspek tersebut dirasakan oleh pengguna melalui kenyamanan fasilitasnya. Lingkungan fasilitas tersebut harus menstimulasi kesadaran positif pasien mengenai dirinya; memperbanyak hubungan dengan alam, budaya, dan orangorang di sekitarnya; mengizinkan privasi; tidak ada kekerasan fisik; menyediakan rangsangan yang bermacam dan bermakna; memperbanyak waktu relaksasi; interaktif; menyeimbangkan konstansi dan fleksibilitas; dan indah [3].

Metode Therapeutic community digunakan dalam proses penyembuhan. Metode penyembuhan tersebut dapat diterapkan melalui konsep therapeutic spaces. Therapeutic spaces dapat dideskripsikan sebagai lingkungan terbangun yang berpusat pada manusia, disiplin evidence-based, yang bertujuan untuk mengidentifikasi dan mendukung elemen spasial yang berinteraksi dengan fisiologi dan psikologi manusia [4].

Untuk menentukan konsep pada rancangan, digunakan Metode Pemrograman oleh Donna P. Duerk. Proses perancangan berangkat dari isu yang digunakan untuk mencari informasi terkait hal-hal yang sudah ada (existing state) dan untuk menciptakan tujuan (goals), kriteria rancang (performance requirements), dan konsep yang dikembangkan untuk mencapai wujud yang diinginkan (future state) [5]. (Gambar 4) Kriteria desain objek rancang diambil dari metode penyembuhan yang diterapkan pada rancangan, poin-poin tersebut adalah:

1) Care in the community (Rancangan harus dapat mendorong dan mengakomodasi terjadinya interaksi dan sosialisasi) (Gambar 5)

2) Design for domesticity (Rancangan harus dapat menciptakan dan memberi suasana seperti di rumah) (Gambar 6)

3) Social valorisation (Rancangan harus dapat menjaga privasi dan keamanan pengguna) (Gambar 7)

4) Integrated with nature (Rancangan harus dapat memanfaatkan dan memaksimalkan elemen-elemen alami di tapak dan sekitarnya) (Gambar 8) [4].

\section{KONSEP DAN EKSPLORASI DESAIN}

Kriteria desain digunakan dalam menentukan konsepkonsep yang diterapkan pada objek rancang. Konsep-konsep kemudian diterapkan pada objek rancang. Konsep-konsep tersebut adalah:

1) Care in the community (Rancangan harus dapat mendorong dan mengakomodasi terjadinya interaksi dan sosialisasi)

a. Sirkulasi terpusat

Memperbanyak kemungkinan terjadi interaksi karena adanya overlap lalu-lalang dan pertemuan user (Gambar 9a)

b. Memperbanyak ruang untuk kegiatan bersama

Ruang-ruang yang memiliki fungsi dan aktifitas serupa digabungkan (Gambar 9b) c. Minimalisasi batas ruang

Batas-batas ruang yang masif hanya untuk ruang yang bersifat privat, selain itu menggunakan ketinggian, furnitur, atau elemen lain yang tidak masif (Gambar 9c)

d. Layout ruang dan susunan massa berupa sosiopetal Layout sedemikian rupa bersifat radial yang dapat menstimulasi terjadinya interaksi sosial (Humphrey O., 1957) (Gambar 9d)

e. Memperbanyak bukaan untuk cahaya matahari Intensitas cahaya matahari yang cukup dapat menstimulasi terjadinya interaksi sosial (Physical Space \& Social Interaction, Jay L.) (Gambar 9e)

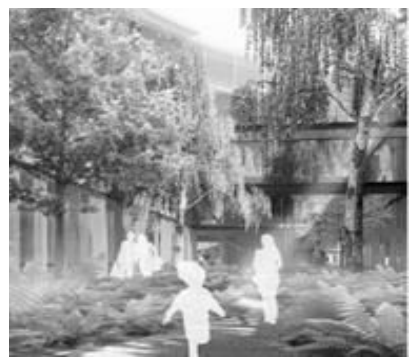

Gambar 3. Ilustrasi Healing Architecture.

Sumber: henninglarsen.com

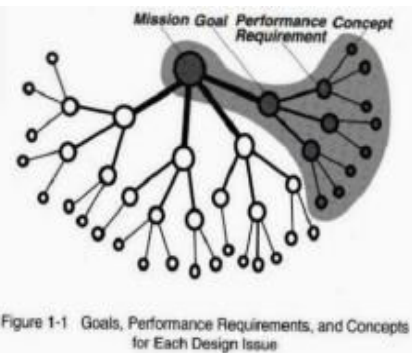

Gambar 4. Metode pemrograman Donna P. Duerk. Sumber: Duerk, 1993

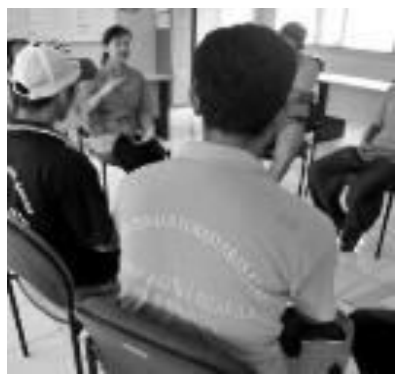

Gambar 5. Ilustrasi care in the community.

Sumber: antaranews.com

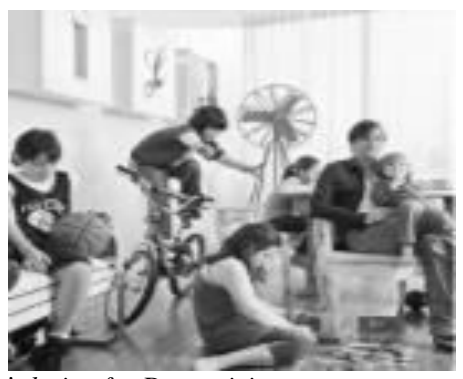

Gambar 6. Ilustrasi design for Domesticity

Sumber: nytimes.com 


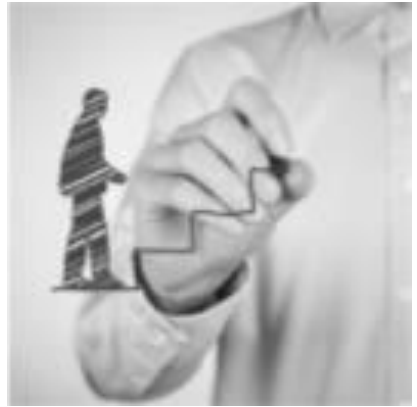

Gambar 7: Ilustrasi social valorisation Sumber: learndirect.com

Gambar 8: Ilustrasi integrated with Nature

Sumber: sensiblehealth.com

2) Design for domesticity (Rancangan harus dapat menciptakan dan memberi suasana seperti di rumah)

a. Menggunakan skala manusia

Skala manusia memberi kesan ramah dan dapat memberi efek psikologis yang baik. (Gambar 10a)

b. Menggunakan warna-warna yang hangat

Memberi kesan ramah, bersahabat dan menenangkan (The Power Of Color in The Healthcare Environment, Laura Guido-Clark Design) (Gambar 10b)

c. Menghindari koridor lurus dan terlalu panjang (>15 meter)

Koridor lurus dan terlalu panjang memberi kesan anti-terapeutik. (American Journal Of Psychiatry, Griffin \& Kashmar) (Gambar 10c)

3) Social valorisation (Rancangan harus dapat menjaga privasi dan keamanan pengguna)

a. Meletakkan ruang yang membutuhkan privasi lebih jauh dari akses atau jalan

Agar fokus dan privasi terjaga. (Gambar a

b. Memiliki satu akses utama yang bisa diawasi (Gambar 11b)

c. Menggunakan material tembus pandang (Gambar 11c)
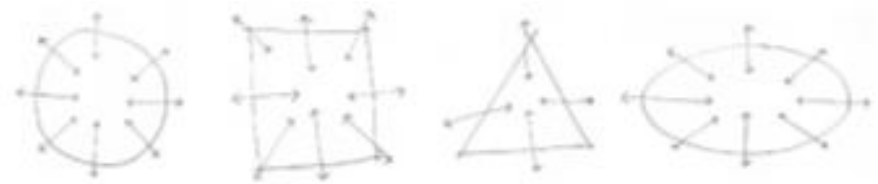
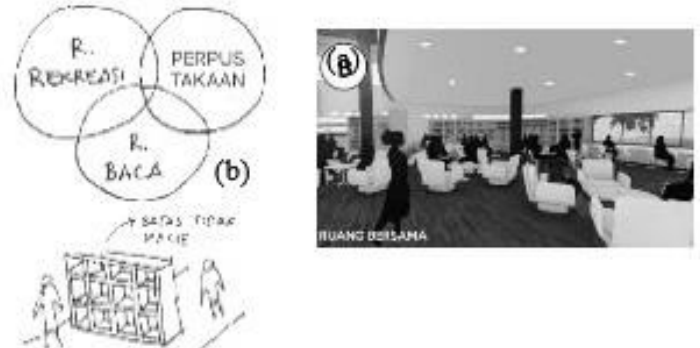

(c)
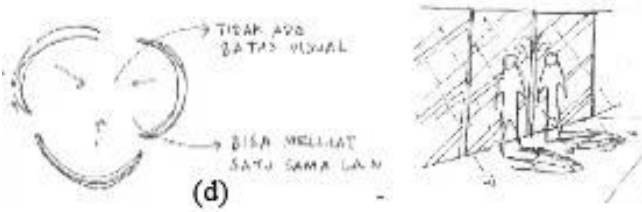

(d)

Gambar 9. Ilustrasi konsep care in the community Sumber: Dokumen pribadi
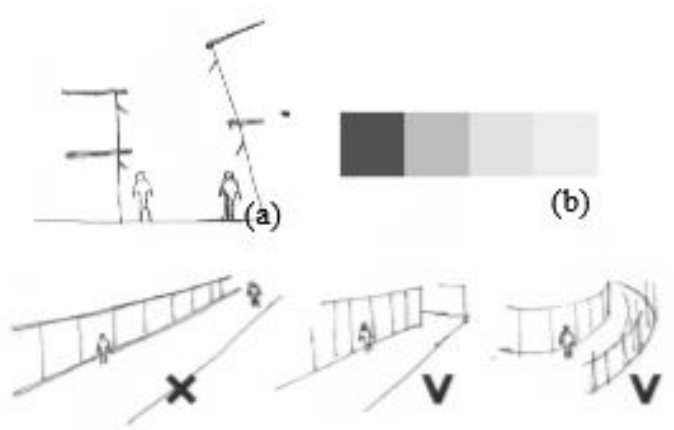

Gambar 10. Ilustrasi konsep design for domesticity Sumber: Dokumen pribadi
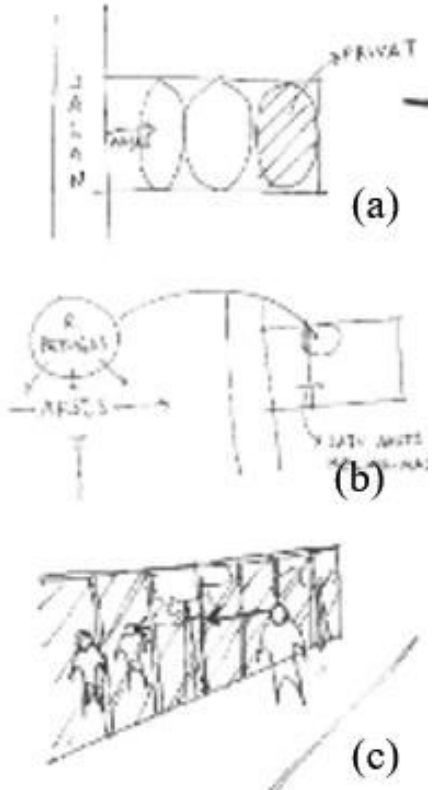

(c)

Gambar 11. Ilustrasi konsep social valorisation Sumber: Dokumen pribadi 
4) Integrated with nature (Rancangan harus dapat memanfaatkan dan memaksimalkan elemen-elemen alami di tapak dan sekitarnya)

a. Memanfaatkan view di sekitar lahan

Di sisi timur lahan terdapat pemandangan gunung Semeru yang dapat dimanfaatkan untuk proses terapi dan kontemplasi. (Gambar 12a)

b. Menggunakan bentuk-bentuk organik dan dinamis

Membaur dengan alam dan mengurangi kesan kaku

c. Memperbanyak taman

Pemanfaatan taman dapat mempercepat proses penyembuhan. (Architectural Healing Environments Thesis, Brian S., 2012) (Gambar 12b)

d. Menggunakan material-material alam Untuk memperkuat kesan alami (Gambar 12c)

Pada kriteria desain poin 4, aspek alami sangat diperhatikan. Pada dasarnya, penerapan konsep therapeutic spaces sangat erat hubungannya dengan alam. Terdapat 2 penerapan konsep tersebut pada objek rancang, yaitu:

1) Terapi holtikultura

Terapi holtikultura menurut yang didefinisikan oleh American Holticultural Therapy Association, adalah kegiatan yang melibatkan seseorang dalam kegiatan tanam-menanam dan berkebun. (Gambar 13) Terdapat program terapeutik dalam terapi ini yang ditujukan salah satunya untuk korban penyalahgunaan narkoba. Melihat keindahan dan melakukan kontak langsung dengan tanaman dapat memicu ketenangan dan kedamaian, memicu emosi positif, dan mengalihkan fokus dari stres [6]. Oleh karena itu, pada objek rancang disediakan fasilitas area tanam-menanam. (Gambar 15a)

2) Therapeutic garden

Merupakan taman di ruang luar yang didesain secara spesifik untuk pengguna tertentu (Holowitz, 2012). Taman tersebut dapat bersifat aktif (digunakan berkegiatan) ataupun pasif (dinikmati). (Gambar 14) Terdapat elemen-elemen yang harus ada di taman tersebut, baik alami maupun terbangun [7]. (Gambar 15b dan 15c) Elemen-elemen tersebut adalah:

a) Alami

- Tanaman yang familiar

- Tanaman yang menarik burung dan kupu-kupu

- Tanaman hias

- Sayur-sayuran

- Tanaman musiman

- Tanah

- Matahari dan naungan alami

- Angin dan hujan

b) Terbangun

- Patio/teras

- Selasar

- Tempat duduk

- Pencahayaan lanskap

- Raised bed

- Naungan

- Air dan ikan

- Keran air

- Outlet listrik outdoor

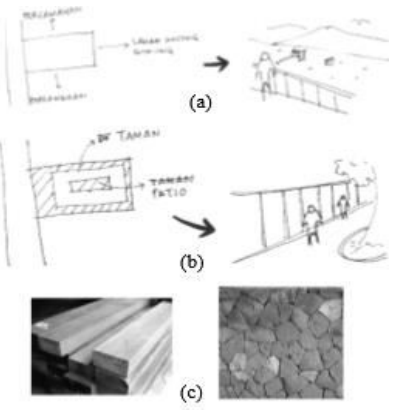

Gambar 12. Ilustrasi konsep integrated with nature.

Sumber: Dokumen pribadi, pinterest.com, seamless-pixels.blogspot.com

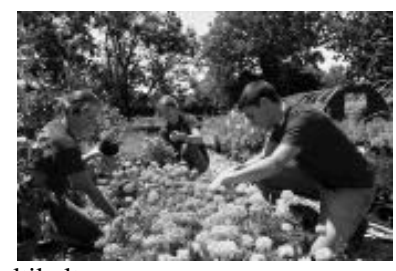

Gambar 13. Terapi holtikultura.

Sumber: adulted.nybg.org

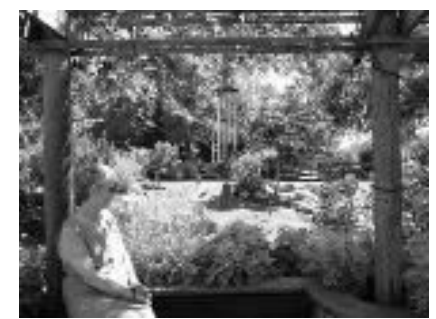

Gambar 14. Terapi holtikultura.

Sumber: worldhealthdesign.com
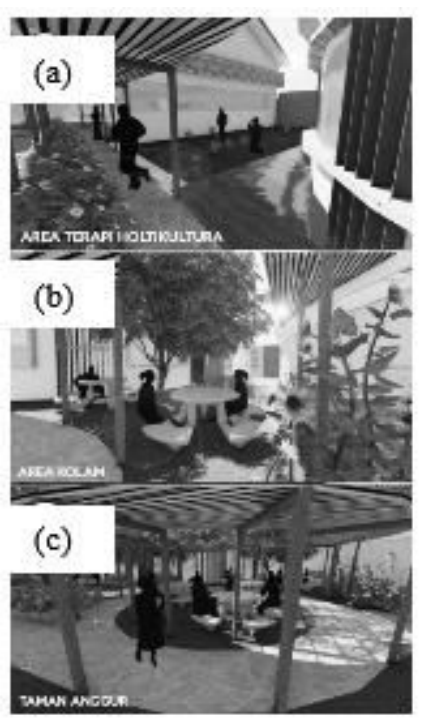

Gambar 15. Ilustrasi penerapan konsep.

Sumber: Dokumen pribadi

3) Eksplorasi tatanan massa

1) Sisi barat adalah yang paling dekat dengan akses jalan. Oleh karena itu semakin ke timur, zonasi dari barat ke timur berjalan dari publik ke privat. (konsep 3.1) (Gambar 18.3) 
2) Massa bangunan untuk terapi diletakkan di sisi paling timur sehingga dapat memanfaatkan view Gunung Semeru. (konsep 4.1) (Gambar 16, 17, 19a)

3) Di tengah lahan diberi ruang terbuka yang berfungsi sebagai sirkulasi terpusat (konsep 1.1) dan ruang terbuka yang bisa digunakan untuk berkegiatan bersama (konsep 1.2). Dengan adanya ruang terbuka tersebut, setiap ruangan mendapat akses langsung terhadap cahaya matahari (konsep 1.5) dan udara alami. (Gambar 16, 17, 19b, 19c)

4) Massa bangunan berada di sekitar ruang terbuka tersebut tanpa ada batas visual (kecuali untuk ruangruang yang bersifat privat) sehingga dapat melihat satu sama lain (sosiopetal-konsep 1.4, minimalisasi bataskonsep 1.3) (Gambar 16 dan 17)

\section{4) Eksplorasi sirkulasi}

1) Sirkulasi pada objek rancang bersifat terpusat, sehingga dapat memicu terjadinya pertemuan antar penghuni dan berinteraksi serta sosialisasi. (konsep 1.1 dan 1.2). Hal tersebut sekaligus meminimalisasi batas antar ruang yang ada. (konsep 1.3) dan mempermudah pengawasan (konsep 3.2) (Gambar 16 dan 17)

2) Pada sirkulasi digunakan bentuk-bentuk melingkar guna mengurangi koridor yang lurus dan terlalu panjang karena dapat menimbulkan kesan antiterapeutik (Griffin \& Kashmar, 1969) (konsep 2.3) (Gambar 16 dan 17)

5) Eksplorasi bentuk

1) Massa menggunakan bentuk-bentuk yang dinamis seperti lengkung dan lingkaran (konsep 4.2) (Gambar 16 dan 17)

2) Layout kamar tidur dibuat melingkar sehingga bersifat sosiopetal dan mempermudah pengawasan (konsep 1.4 dan 3.2) (Gambar 16 dan 17)

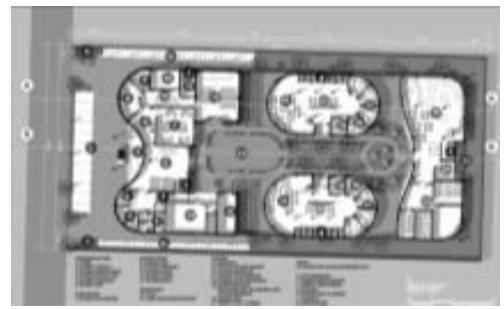

Gambar 16. Denah lantai 1.

Sumber: Dokumen Pribadi

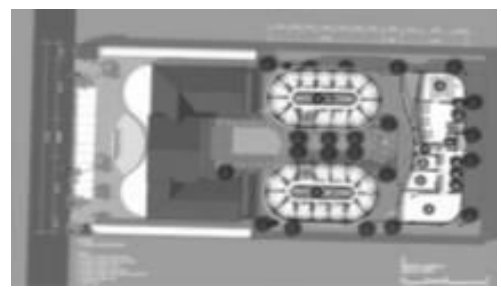

Gambar 17. Denah lantai 2.

Sumber: Dokumen Pribadi

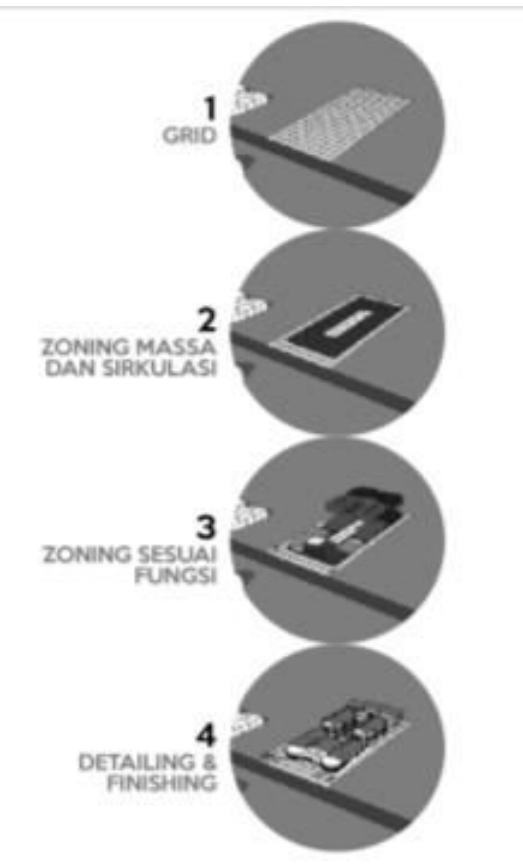

Gambar 18. Proses pengaplikasian kriteria desain ke konsep. Sumber: Dokumen Pribadi

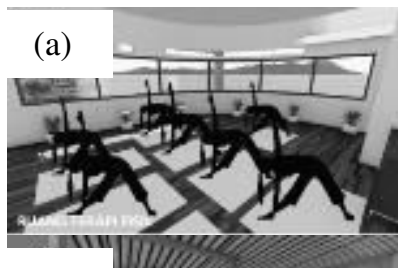

(b)

Gambar 19. Denah lantai 2.

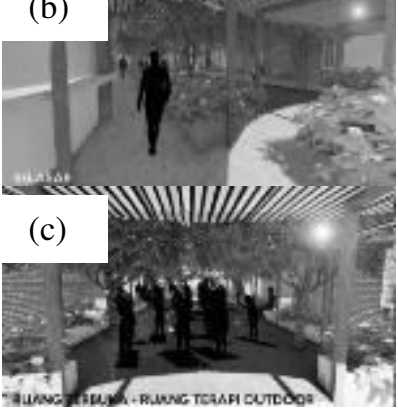

Sumber: Dokumen Pribadi

\section{KESIMPULAN}

Proses merancang sebuah fasilitas kesehatan memerlukan pendekatan yang selaras dengan proses penyembuhan pasien di dalamnya agar arsitektur dapat mendukung dan mempercepat proses penyembuhan. "Rumah Rehabilitasi Sosial Bagi Korban Narkoba" merupakan sebuah objek arsitektural berupa fasilitas kesehatan yang pada proses rancangnya menggunakan pendekatan healing architecture serta konsep therapeutic spaces yang berkorelasi dengan metode penyembuhan korban narkoba yang sering digunakan di Indonesia yaitu therapeutic community. Objek rancang menghadirkan ruang-ruang yang memicu dan memfasilitasi terjadinya interaksi sosial serta memiliki aspek alami yang sangat kuat. Hal-hal tersebut dapat mendukung proses 
rehabilitasi korban narkoba sehingga mereka dapat menjadi produktif dan kembali ke masyarakat.

\section{DAFTAR PUSTAKA}

[1] K. Mardiyansyah, "Indonesia Darurat Narkoba, Menpora Inginkan Pemuda Bernyali," Okezone.com, 2016. [Online]. Available: http://news.okezone.com/read/2016/07/22/519/1444768/indonesiadarurat-narkoba-menpora-inginkan-pemuda-bernyali.
[2] K. Ariwibowo, "Therapeutic Community," 2012.

[3] B. Schaller, "Architectural Healing Environments," 2012.

[4] E. Chrysikou, Architecture for Psychiatric Environments and Therapeutic Spaces. 2014.

[5] D. P. Duerk, Architectural Programming- information management for design. 1993.

[6] M. Barrett, Creating Eden: The Garden as a Healing Space. 1992.

[7] S. Holowitz, "Therapeutic Gardens and Horticultural Therapy: Growing Roles in Health Care,” 2012. 